\title{
The effect of vitamin D on clinical manifestations and activity of Behçet's disease
}

\author{
Nurşad Aslan ${ }^{1}$, Kamile Demirci², Tuba Güler ${ }^{3}$, Fulya Dörtbaş ${ }^{4}$, Ebru Kale ${ }^{5}$ \\ 1Department of Dermatology, Kocaeli Derince Training and Research Hospital, Kocaeli, Turkey \\ ${ }^{2}$ Department of Dermatology, Gölcük Necati Çelik State Hospital, Kocaeli, Turkey \\ ${ }^{3}$ Department of Physical Therapy and Rehabilitation, Kocaeli Derince Training and Research Hospital, Kocaeli, Turkey \\ ${ }^{4}$ Department of Rheumatology, Kocaeli Derince Training and Research Hospital, Kocaeli, Turkey \\ ${ }^{5}$ Department of Biochemistry, Kocaeli Derince Training and Research Hospital, Kocaeli, Turkey
}

Adv Dermatol Allergol 2017; XXXIV (1): 15-20

DOI: https://doi.org/10.5114/pdia.2016.57222

\begin{abstract}
Introduction: Immune mechanisms have been implemented to have a role in the pathogenesis of Behçet's disease (BD) and vitamin $\mathrm{D}$ has been shown to have a regulatory role in the immune system function.

Aim: To evaluate the vitamin D levels of BD patients and its relationship between clinical findings and disease activity of BD.

Material and methods: Sixty-eight patients with BD and 70 age- and sex-matched controls were examined retrospectively. Demographic features, vitamin D levels for both groups and clinical findings, disease activity, drug usage for BD patients were examined from their medical reports. Disease activity was calculated for each patient according to Krause's BD activity assessment.

Results: Mean vitamin D levels of patients and controls were $15.35 \pm 7.18 \mathrm{ng} / \mathrm{ml}$ and $18.44 \pm 5.79 \mathrm{ng} / \mathrm{ml}$, respectively. Vitamin D levels were significantly lower in BD patients than in controls $(p=0.006)$. Mean vitamin $D$ levels of active and inactive BD cases were $15.68 \pm 7.31 \mathrm{ng} / \mathrm{ml}$ and $15.08 \pm 7.17 \mathrm{ng} / \mathrm{ml}$, respectively $(p=0.73)$. Disease activity of patients using and not using vitamin D was similar $(p=0.51)$.

Conclusions: Significantly lower levels of vitamin D were observed in BD patients. Our results indicate that there is no correlation between BD activity and a vitamin D level. Together with these, vitamin D replacement treatment was found to have no effect on disease activity.
\end{abstract}

Key words: vitamin D, immune-inflammatory diseases, Behçet’s disease.

\section{Introduction}

Behçet's disease (BD) is a chronic disease that involves multiple organ systems with characteristic recurrent orogenital ulcerations [1]. In the etiopathogenesis of BD, genetic factors, environmental factors such as microbial agents and immune mechanisms have been suggested as causative factors [2].

Vitamin $D$ has been known to be important in the metabolism of calcium (Ca) and phosphorus (P). Yet there is an increasing body of evidence emphasizing its anti-inflammatory and immunomodulatory effects [3, 4]. Immunomodulatory effects of vitamin D include suppression of T helper1 (Th1) and Th17 cells, stimulation of regulatory T-cells, inhibiting B-lymphocyte differentiation and immunoglobulin secretion, suppression of antigen presenting activity of macrophages to lymphocytes and differentiation of monocytes into dendritic cells (DC) and their T cell stimulatory activity [5-7].
Lower vitamin D levels have been reported in some autoimmune and inflammatory diseases [8-15]. There have been few reports investigating the effect of vitamin $D$ on $\mathrm{BD}$ patients [16-19].

\section{Aim}

We planned this study to evaluate the vitamin D levels in BD patients and to investigate whether there is a relationship between vitamin $\mathrm{D}$ status and clinical findings and disease activity of BD.

\section{Material and methods}

The study design was approved by the Ethics Committee of the Kocaeli University Faculty of Medicine. Medical records of 68 patients with BD and 70 age- and sexmatched healthy controls were examined retrospectively.

Address for correspondence: Dr. Nurşad Aslan, Department of Dermatology, Kocaeli Derince Training and Research Hospital, 41000 Kocaeli, Turkey, phone: +90 5065047793, e-mail: nuradaslan@yahoo.com Received: 28.08.2015, accepted: 15.11.2015. 
Table 1. Krause's Behçet's disease activity assessment

\begin{tabular}{ll}
\hline Mild & Mouth ulcers \\
& Genital ulcers \\
& Skin lesions (erythema nodosum, papulopustular \\
& eruption, folliculitis, leukocytoclastic vasculitis) \\
& Arthralgia \\
& Recurrent headaches \\
& Epididymitis \\
& Mild gastrointestinal symptoms (chronic diarrhea, \\
chronic recurrent colicky abdominal pain) \\
Pleuritic pain \\
Superficial vein thrombosis \\
\hline Moderate & Arthritis \\
& Deep vein thrombosis of the leg \\
& Anterior uveitis \\
& Gastrointestinal bleeding \\
\hline Severe & Posterior/pan uveitis, retinal vasculitis \\
& Arterial thrombosis or aneurysm \\
& Large vessel (vena cava, hepatic) thrombosis \\
& Neuro-Behçet \\
& Intestinal perforation
\end{tabular}

Patients that were diagnosed with $\mathrm{BD}$ according to the International Study Group criteria for BD which have been followed in dermatology, ophthalmology, rheumatology, neurology outpatient clinics between January 2013 and December 2014 were included in the study [20]. Data including serum 25-hydroxivitamin D levels and demographic features, currently used drugs, clinical manifestations of patients at the time of measurement of vitamin D were collected from medical records. The clinical activity index for each patient was calculated by using Krause's BD activity assessment at the time of vitamin D measurement [21]. The Krause's BD activity assessment criteria are shown in Table 1.

A control group was created retrospectively from medical records of individuals who visited other outpatient clinics and had their vitamin D levels measured. Controls with a history of any drug use such as vitamin D, multivitamin, corticosteroids and drugs affecting bone metabolism in their medical records were excluded.

For both groups, individuals with a history of chronic diseases including renal or hepatic diseases, thyroid diseases, rheumatological diseases, bone metabolic diseases, malabsorption, type 1 diabetes mellitus or malignancies were also excluded from the study.

Much attention is paid in order to exclude the seasonal differences of vitamin D measurements in both

Table 2. Distribution of measurement of vitamin D according to seasons in both groups

\begin{tabular}{lcccccc}
\hline Group & \multicolumn{5}{c}{ Season } \\
\cline { 2 - 7 } & Summer & Winter & Spring & Autumn & P-value \\
\hline Patients $\left(n^{*}\right)$ & 17 & 15 & 21 & 15 & $>0.05$ \\
\hline Control $(n)$ & 11 & 23 & 18 & 18 & $(0.32)$ \\
\hline${ }^{*}$ Case number. & & & & &
\end{tabular}

groups. For this, individuals in the control group were chosen from those whose vitamin D levels were measured in the same seasons as BD patients.

Levels of serum 25-hydroxivitamin D were measured in the Gamma Counter device by using $250 \mathrm{H}$-vit $\mathrm{D}_{3}$ radioimmunoassay (RIA) kits (Beckman Coulter, Brea, CA, USA). Serum calcium ( $\mathrm{Ca}$ ) and phosphorus (P) levels were measured by using standard laboratory tests in Abbott/ Architech 16000 autoanalyser and serum parathyroid hormone (PTH) levels were measured by Advia Centaur hormone analyser.

Vitamin D levels lower than $20 \mathrm{ng} / \mathrm{ml}$ were classified as 'vitamin D deficiency' and lower than $5 \mathrm{ng} / \mathrm{ml}$ were classified as 'heavy vitamin D deficiency' category. Vitamin D levels between 20-30 ng/ml were classified as 'vitamin D insufficiency' and higher than $30 \mathrm{ng} / \mathrm{ml}$ of vitamin D were categorized as 'normal' [3]. Serum calcium levels of $8.5-10.5 \mathrm{mg} / \mathrm{dl}$ and serum phosphorus levels of $2.3-4.7 \mathrm{mg} / \mathrm{dl}$ were considered to be normal. Parathyroid hormone levels of 10-65 of $\mathrm{pg} / \mathrm{ml}$ were defined as normal [22].

\section{Statistical analysis}

Demographic features of groups were analyzed using descriptive statistics. Among the different groups, we used independent $t$-test and one-way ANOVA tests to compare variables. Differences in the rates of low serum 25 -hydroxivitamin $\mathrm{D}$ levels between active and inactive $\mathrm{BD}$ groups were analyzed using the $\chi^{2}$ test, and they were presented with estimated odds ratio (OR; 95\%). Seasonal distributions of patients and control groups and vitamin D categories of study groups were analyzed with crosstabs. To determine the effect of colchicine and systemic corticosteroid treatment on serum 25 -hydroxivitamin D in BD patients, independent $t$-test was used between the drug users and nonusers groups. A two-sided $p$-value $<0.05$ was considered statistically significant. Statistical analysis was performed using SPSS 17 (Chicago, IL) pack program.

\section{Results}

25-hydroxyvitamin D serum values of 68 patients with BD and 70 age- and sex-matched healthy controls were compared. The male/female ratio of patients and controls was $31 / 37$ and $34 / 36$, respectively $(p>0.05)$. The mean 25-hydroxyvitamin D levels in the BD group and control group were $15.35 \pm 7.18 \mathrm{ng} / \mathrm{ml}$ and $18.44 \pm 5.79 \mathrm{ng} /$ $\mathrm{ml}$, respectively. The mean 25 -hydroxyvitamin D was significantly lower in BD patients $(p=0.006)$.

Mean Ca, P and PTH levels were $9.55 \pm 0.42 \mathrm{mg} / \mathrm{dl}$, $3.46 \pm 0.55 \mathrm{mg} / \mathrm{dl}, 63.24 \pm 41.77 \mathrm{pg} / \mathrm{ml}$, respectively for the patient group and $9.52 \pm 0.44 \mathrm{mg} / \mathrm{dl}, 3.37 \pm 0.48 \mathrm{mg} / \mathrm{dl}$, $63.89 \pm 34.78 \mathrm{pg} / \mathrm{ml}$ for the control group. These results were statistically similar for both groups $(p>0.05)$.

Table 2 shows the distribution of measurement of vitamin $\mathrm{D}$ according to seasons in both groups. The num- 
ber of subjects whose vitamin D levels were measured for the same season were similar between two groups ( $p>0.05$ for all seasons).

According to Krause's activity index, we classified patients as mild, moderate and severe. Disease activity of Behçet's patients at the time when vitamin D levels measured are shown in Table 3. Thirty-one (45.6\%) BD patients were active, 37 (54.4\%) of them were in remission. Twenty $(29.4 \%)$ of those active patients were mild, $10(14.7 \%)$ of them were moderate and one (1.5\%) was severe. The mean 25 -hydroxyvitamin D level in the active $\mathrm{BD}$ patients was $18 \pm 7.31 \mathrm{ng} / \mathrm{ml}$ and inactive stage of BD patients was $15.08 \pm 7.17 \mathrm{ng} / \mathrm{ml}$. The difference between these 2 patient groups was not statistically significant ( $p$ $=0.73$ ). Only in 1 patient which was accepted as severe active, vitamin D level was $7.5 \mathrm{ng} / \mathrm{ml}$.

Vitamin D categories in both groups are shown in Table 4. There was no statistically significant difference between groups according to vitamin $\mathrm{D}$ categories $(p>$ 0.05). Vitamin D deficiency $(5-20 \mathrm{ng} / \mathrm{ml})$ was common in both groups. But heavy deficiency $(<5 \mathrm{ng} / \mathrm{ml})$ was detected only in the patient group.

In the current study, 12 (17.6\%) BD patients were under vitamin D treatment. Five (41.7\%) of them had active disease, 7 (58.3\%) of them were in remission. Among active disease patients, 3 were under vitamin $D$ treatment for 6 months, 2 of them for 10 months and 2 of them for more than 1 year. The disease activity changed from moderate to mild only in one patient that was under vitamin D treatment. In others, the activity was similar before and after treatment. Among BD patients who were not using vitamin D, 26 (46.4\%) of them had active disease and 30 (53.6\%) of them were in remission. Disease activity was found to be similar in patients who used and did not use vitamin $\mathrm{D}(p=0.51)$.

Vitamin D levels of individuals with and without major clinical manifestations are shown in Table 5. The correlation between oral aphthous ulcer and vitamin $D$ level was found to be non-significant $(p=0.87)$. But we did not evaluate the relation between 25 -hydroxyvitamin $D$
Table 3. Classification of Behçet disease patients according to Krause's Activity Index

\begin{tabular}{lcc}
\hline $\begin{array}{l}\text { Activity } \\
\text { of disease }\end{array}$ & $\begin{array}{c}\text { Case } \\
\text { number }\end{array}$ & $\begin{array}{c}\text { 25-hydroxivitamin D level } \\
{[\mathrm{ng} / \mathrm{ml}]}\end{array}$ \\
\hline Active: & $31(45.6 \%)$ & $15.68 \pm 7.31$ \\
\hline Mild & $20(29.4 \%)$ & $14.47 \pm 6.73$ \\
\hline Moderate & $10(14.7 \%)$ & $16.11 \pm 8.46$ \\
\hline Severe & $1(1.5 \%)$ & 7.5 \\
\hline Inactive & $37(54.4 \%)$ & $15.08 \pm 7.17$ \\
\hline
\end{tabular}

Table 4. Vitamin D categories in the study groups

\begin{tabular}{lccc}
\hline $\begin{array}{l}\text { 25-hydroxyvitamin D } \\
\text { groups }\end{array}$ & $\begin{array}{c}\text { Behçet's } \\
\text { disease } \\
\text { group }\end{array}$ & $\begin{array}{c}\text { Control } \\
\text { group }\end{array}$ & $P$-value \\
\hline Sufficient $>30 \mathrm{ng} / \mathrm{ml}$ & $3(4.4 \%)$ & $2(2.9 \%)$ & 0.052 \\
\hline Insufficient $21-29 \mathrm{ng} / \mathrm{ml}$ & $11(16.2 \%)$ & $22(31.4 \%)$ & \\
\hline Deficiency $5-20 \mathrm{ng} / \mathrm{ml}$ & $49(72.1 \%)$ & $46(65.7 \%)$ & \\
\hline Heavy deficiency $<5 \mathrm{ng} / \mathrm{ml}$ & $5(7.4 \%)$ & $0(0 \%)$ & \\
\hline
\end{tabular}

levels and other clinical manifestations due to the small size of each group.

Forty-seven (69\%) BD patients were using colchicine and 14 of them were using corticosteroids. The mean vitamin D level in cases using colchicine was $15.22 \pm 7.1 \mathrm{ng} /$ $\mathrm{ml}$ and in cases not using colchicine was $15.66 \pm 7.53 \mathrm{ng} /$ $\mathrm{ml}(p=0.81)$. The mean vitamin D level in corticosteroids using cases was $16.29 \pm 6.41 \mathrm{ng} / \mathrm{ml}$, and in cases not using corticosteroids was $15.11 \pm 7.41 \mathrm{ng} / \mathrm{ml}(p=0.56)$.

\section{Discussion}

Immune system alterations have been implemented to have a role in the pathogenesis of BD. Genetic and environmental factors determine the inflammatory process $[1,2]$. The inflammation is generally mediated by Th1 mediated cytokines such as tumor necrosis factor- $\alpha$ (TNF- $\alpha$ ), interleukin-6 (IL-6) and IL-18 [23]. On the other hand, infectious agents such as Streptococci and Mycoplasma,

Table 5. Major symptoms of Behçet's disease and 25-hydroxyvitamin D value

\begin{tabular}{|c|c|c|c|c|}
\hline \multirow[t]{2}{*}{ Major symptoms } & \multicolumn{2}{|r|}{ Present } & \multicolumn{2}{|r|}{ Not present } \\
\hline & $N$ & 25-hydroxyvitamin D & $N$ & 25-hydroxyvitamin D \\
\hline Oral aphthous ulcer & 23 & $15.55 \pm 6.77$ & 45 & $15.18 \pm 7.53$ \\
\hline Genital ulcer & 3 & $15.85 \pm 4.47$ & 65 & $15.28 \pm 7.35$ \\
\hline Erythema nodosum & 4 & $11.2 \pm 7.39$ & 64 & $15.57 \pm 7.2$ \\
\hline Pseudofolliculitis & 7 & $15.97 \pm 8.2$ & 61 & $15.23 \pm 7.18$ \\
\hline Vascular involvement & 5 & $13.92 \pm 4.19$ & 63 & $15.47 \pm 7.38$ \\
\hline Arthritis & 6 & $17.20 \pm 9.88$ & 62 & $15.17 \pm 6.95$ \\
\hline Ocular involvement & 1 & $4.43 \pm 0$ & 67 & $15.47 \pm 7.15$ \\
\hline Neurological involvement & 1 & $11.40 \pm 0$ & 67 & $15.41 \pm 7.22$ \\
\hline
\end{tabular}


and their reaction with HSP60 have been reported to initiate the innate immune system activation in BD [24]. During the active phase of BD, especially CD4+ T lymphocytes are intensively stimulated [19, 24, 25]. A higher expression of TLR2 and TLR 4 was also mentioned in the immunopathogenesis of BD activation $[26,27]$.

Vitamin $\mathrm{D}$ has been shown to have a regulatory role in the immune system function. Th1, Th2 and regulatory $T$ cells, B lymphocytes, macrophages and dendritic cells have been shown to express the vitamin $D$ receptor (VDR) and to be vitamin D targets [9, 28]. Vitamin D has a suppressive role on Th1 cell proliferation and on production of TNF- $\alpha$, iterferon (IFN)- $\gamma$, IL-2, IL-5, and it has stimulatory effect on Th2 cell differentiation [28]. It has been postulated that vitamin $D$ deficiency results in diminished regulator T-cells and shifts Th1/Th2 ratio toward Th1 $[6,7]$. Also a down-regulatory effect of vitamin D on TLR2 and TLR4 had been reported before [29].

These immunomodulatory effects of vitamin D led the researchers to investigate a relationship between vitamin D levels and BD [16-19, 27]. Most of these studies reported significantly lower levels of serum vitamin $D$ in $\mathrm{BD}$ in comparison with normal controls $[16,18,27$, 30]. Only in one study, the 25 -hydroxyvitamin D level in the BD group was found to be higher than in the control group [19]. In accordance with other studies, in our study the mean 25-hydroxyvitamin D level in the BD group was found to be lower than in the control group.

In recent studies vitamin D deficiency was found to be common in our country [31]. Consistently, vitamin D deficiency was common in both patient and control groups in our study. In the control group, there was no history of chronic disease and drug use that can affect the vitamin D levels, but they had a health problem that would cause them to come to the hospital such as fatigue and nonspecific pain. But despite this condition, the mean vitamin $D$ level of the patient group was lower. Also heavy deficiency $(<5 \mathrm{ng} / \mathrm{ml})$ was detected only in the patient group.

Some studies were performed to understand the relationship between the vitamin $\mathrm{D}$ level and disease activity in BD. However most of them were unable to establish a clear relationship between disease activity and vitamin D levels.

In a study by Do et al., vitamin D levels were found to be lower in the active BD group, but the difference between the active group and the inactive group was not statistically significant [27]. Likewise, in another study by Khabbazi et al., a lower level of vitamin D in active BD cases in comparison with the control group was found but these results did not reveal a significant correlation between disease activity and major symptoms of BD and vitamin D values [18].

In a wider study by Hamzaoui et al., a lower level of vitamin $D$ in active $B D$ cases in comparison with silent $\mathrm{BD}$ cases and the control group was found and these re- sults revealed a significant correlation between disease activity and the vitamin D level [17]. There are also other reports confirming a positive relation between BD activity and vitamin D deficiency $[27,30]$.

In our study, the mean 25-hydroxyvitamin D level in active and inactive BD patients were similar. We did not reveal a significant difference in vitamin $D$ levels in mild and moderate active groups. But in severe active patient, the vitamin D level was significantly lower than in others (Table 2).

We did not evaluate the relation between 25-hydroxyvitamin D levels and clinical manifestations such as genital ulcer, erythema nodosum, pseudofolliculitis, vascular involvement, arthritis, ocular involvement, neurological involvement in BD subgroups due to the small size of each group. Only the correlation between the oral aphthous ulcer and vitamin D level was evaluated and found to be non-significant. But in patients with ocular involvement there was a striking vitamin D deficiency (Table 4). At the same time heavy vitamin D deficiency was seen in 5 BD patients. Three of these 5 patients with heavy vitamin $D$ deficiency were in remission. Uveitis, oral aphthous ulcers and erythema nodosum were seen in other 2 patients. In our patient group, $61 \%$ of active BD cases were mildly-active, $35 \%$ of them were moderately active, only one patient was accepted as severe BD.

So we think that larger study groups including moderately active and severe active BD cases must be arranged to better understand the relation between vitamin $\mathrm{D}$ levels and disease activity and organ involvement in BD patients.

The mechanism of lower vitamin D levels in active BD stage are not yet elucidated. Khabbazi et al. reported that a vitamin $D$ deficiency is a triggering factor in activation of $\mathrm{BD}$ [18]. On the other hand, Hamzaoui et al. reported that during the active stage of $\mathrm{BD}, \mathrm{CD} 4+\mathrm{T}$ cells increase five-fold and VDR's on these T cells bind vitamin D and this may result in intrinsic vitamin D consumption [17]. In addition there is a study which reports that lower vitamin D levels may develop as a result of colchicine use [16].

In our study, vitamin D levels were found to be similar in active and inactive patients. We were also able to evaluate the effect of colchicine on vitamin D levels in our patient group. In our study we did not find a significant relationship between colchicine usage and vitamin D levels.

It is not yet understood whether the disease activation is a result of a lower vitamin D level or a lower vitamin $D$ level is a result of active inflammation. Intrinsic genetic factors are known to play a role in BD ethiopathogenesis. So we thought that the lower vitamin D level may be due to genetic predisposition.

In a previous study by Can et al., replacement of vitamin $D$ has been reported to cause an improvement in endothelial functions in BD patients, but this was not statistically significant [30]. Do et al. also reported that 
inflammation triggered by TLR2 and TLR4 was significantly down-regulated by vitamin $\mathrm{D}$ replacement [27].

In the current study, disease activity was found to be similar in patients who used and did not use vitamin D. Also in a drug user group, the activity indexes were similar before and after treatment. Only in 1 patient that was under treatment of vitamin D, the disease activity changed from moderate to mild. But in this patient, besides vitamin D, immunosuppressive agents had been also added for the treatment of disease. In our study there was no correlation between disease activity and being under treatment of vitamin D. However, the current study was retrospective and it is not enough to say there is no benefit of vitamin D replacement, larger prospective studies must be done.

To our knowledge, our study is the largest and also the first study investigating the relationship between vitamin D levels and disease activity reported from Turkey. In other previous studies, seasonal distribution of vitamin D levels was not homogeneous and not similar to the control group. In our study, seasonal variabilities were excluded in order to make a reliable analysis.

The study had some limitations. Because our study was retrospective, we could not evaluate the disease activity according to more reliable Behçet Disease Current Activity Form. Also we could not evaluate some factors such as nutrition, smoking habits, alcohol usage, body mass index, genetic predisposition, physical activity, clothing style of patients and controls.

\section{Conclusions}

In our study, a high prevalence of vitamin D deficiency was observed in BD patients. Our results indicate that there is no correlation between BD activity and the vitamin D level. We could not correlate major clinical findings and 25-hydroxyvitamin D levels in BD subgroups due to the small size of each group. Together with these, vitamin $D$ replacement treatment was found to have no effect on disease activity. However, more scrutinized and prospective studies are warranted to address the issue of vitamin $\mathrm{D}$ deficiency in $\mathrm{BD}$, and its relation with disease activity and effect of replacement of vitamin D on disease activity.

\section{Conflict of interest}

The authors declare no conflict of interest.

\section{References}

1. Saadoun D, Wechsler B. Behçet's disease. Orphanet J Rare Dis 2012; 7: 20.

2. Alpsoy E. Behçet disease: an update in ethiopathogenesis. Turk J Dermatol 2013; 7: 41-5.

3. Holick MF. Vitamin D deficiency. N Engl J Med 2007; 357: 266-81.
4. Arnson Y, Amital H, Shoenfeld Y. Vitamin D autoimmunity: new aetiological and therapeutic considerations. Ann Rheum Dis 2007; 66: 1137-42.

5. Griffin MD, Lutz W, Phan VA, et al. Dendritic cell modulation by 1alpha,25 dihydroxyvitamin D3 and its analogs: a vitamin $\mathrm{D}$ receptor-dependent pathway that promotes a persistent state of immaturity in vitro and in vivo. Proc Natl Acad Sci USA 2001; 98: 6800-5.

6. Veldman CM, Cantorna MT, DeLuca HF. Expression of 1,25-dihydroxyvitamin D(3) receptor in the immune system. Arch Biochem Biophys 2000; 374: 334-8.

7. Penna G, Roncari A, Amuchastegui S, et al. Expression of the inhibitory receptor ILT3 on dendritic cells is dispensable for induction of CD4+ Foxp3+ regulatory T cells by 1,25-dihydroxyvitamin D3. Blood 2005; 106: 3490-7.

8. Cutolo M. Vitamin D and autoimmune rheumatic diseases. Rheumatology (Oxford) 2009; 48: 210-2.

9. Kamen D, Aranow C. Vitamin D in systemic lupus erythematosus. Curr Opin Rheumatol 2008; 20: 532-7.

10. Heidari B, Hajian-Tilaki K, Heidari P. The status of serum vitamin $D$ in patients with rheumatoid arthritis and undifferentiated inflammatory arthritis compared with controls. Rheumatol Int 2012; 32: 991-5.

11. Munger KL, Levin LI, Hollis BW, et al. Serum 25-hydroxyvitamin D levels and risk of multiple sclerosis. J Am Med Assoc 2006; 296: 2832-8.

12. Cigolini M, Iagulli MP, Miconi V, et al. Serum 25-hydroxyvitamin D3 concentrations and prevalence of cardiovascular disease among type 2 diabetic patients. Diabetes Care 2006; 29: 722-4.

13. Pappa HM, Grand RJ, Gordon CM. Report on the vitamin D status of adult and pediatric patients with inflammatory bowel disease and its significance for bone health and disease. Inflamm Bowel Dis 2006; 12: 1162-74.

14. Bergler-Czop B, Brzezińska-Wcisło L. Serum vitamin D level - the effect on the clinical course of psoriasis. Adv Dermatol Allergol 2016; 33: 445-9.

15. Karagün E, Ergin C, Baysak S, et al. The role of serum vitamin D levels in vitiligo. Adv Dermatol Allergol 2016; 33 : 300-2.

16. Karatay S, Yıldırım K, Karakuzu A, et al. Vitamin D status in patients with Behçet's disease. Clinics 2011; 66: 721-3.

17. Hamzaoui K, Ben Dhifallah I, Karray E, et al. Vitamin D modulates peripheral immunity in patients with Behcet's disease. Clin Exp Rheumatol 2010; 28 (4 Suppl. 60): 50-7.

18. Khabbazi A, Rashtchizadeh N, Ghorbanihaghjo A, et al. The status of serum vitamin D in patients with active Behçet's disease compared with controls. Int I Rheum dis 2014; 17: 430-4.

19. Faezi ST, Ansari N, Paragomi P, et al. Vitamin D deficiency in patients with Behçet's disease. J Diab Metabol Disord 2014; 13: 18.

20. International Study Group for Behcet's disease. Criteria for diagnosis of Behcet's disease. Lancet 1990; 335: 1078-80.

21. Türsen Ü. Activation markers in Behcet disease. Turkderm 2009; 43: 74-86.

22. Alan HB Wu. Tietz Clinical Guide to Laboratory Tests. Güneş Tip Kitapevleri, Ankara, Turkey 2011.

23. Raziuddin S, Al-Dalaan A, Bahabri S, et al. Divergent cytokine production profile in Behçet's disease: altered Th1/Th2 cell cytokine pattern. J Rheumatol 1998; 25: 329-33.

24. Direskeneli H, Saruhan-Direskeneli G. The role heat shock proteins in Behçet's disease. Clin Exp Rheumatol 2003; 21: 44-8. 
25. Dalghous AM, Freysdottır J, Fortune F. Expression of cytokines and chemokine receptors in oral ulcers of patients with Behçet's disease and recurrent aphthous stomatitis is Th1 associated, although Th2 association is also observed in patients with Behçet's disease. Scand I Rheumatol 2006; 35: 472-5.

26. Kahan A, Hamzai K, Ayed K. Abnormalities of T lymphocytes subsets in Behçet's disease demonstrated with anti-CD45RA and anti-CD29 monoclonal antibodies. J Rheumatol 1992; 19: 742-6.

27. Do JE, Kwon SY, Park S, Lee ES. Effects of vitamin D on expression of Toll-like receptors of monocytes from patients with Behcet's disease. Rheumatology (Oxford) 2008; 47: 840-8.

28. Mahon BD, Wittke A, Weaver V, Cantorna MT. The targets of vitamin $D$ depend on the differentiation and activation status of CD4 positive T cells. J Cell Biochem 2003; 89: 922-32.

29. Sadeghi K, Wessner B, Lagnerr U, et al. Vitamin D3 down regulates monocyte TLR expression and triggers hyporesponsiveness to pathogen-associated molecular patern. Eur J Immunol 2006; 36: 361-70.

30. Can M, Gunes M, Haliloglu OA, et al. Effect of vitamin D deficiency and replacement on endothelial functions in Behcet's disease. Clin Exp Rheumatol 2012; 30 (3 Suppl. 72): S57-61.

31. Fidan F, Alkan BM, Tosun A. Çağın pandemisi: D vitamin eksikliği ve yetersizliği. Türk Osteoporoz Dergisi 2014; 20 : 71-4. 